\title{
Prevalence and risk factors for Equine Infectious Anemia in Poconé municipality, northern Brazilian Pantanal
}

\author{
Alice M.C.M. Borges ${ }^{a}$, Lucas G. Silva ${ }^{a}$, Márcia F. Nogueira ${ }^{b}$, Anderson C.S. Oliveira ${ }^{c}$, Neuber J. Segri ${ }^{c}$, \\ Fernando Ferreira $^{\mathrm{d}}$, Rute Witter ${ }^{\mathrm{e}}$, Daniel M. Aguiar ${ }^{\mathrm{e}, *}$ \\ a Associação Brasileira dos Criadores de Cavalo Pantaneiro, Programa de Pós-Graduação em Ciências Veterinárias da Faculdade de Agronomia, Medicina Veterinária e Zootecnia, \\ Universidade Federal de Mato Grosso, Cuiabá, CEP78060-900, Brazil \\ ${ }^{\mathrm{b}}$ Empresa Brasileira de Pesquisa Agropecuária - EMBRAPA Pantanal, Corumbá, CEP79320-900, Brazil \\ ${ }^{\mathrm{c}}$ Departamento de Estatística, Instituto de Ciências Exatas e da Terra, Universidade Federal de Mato Grosso, Cuiabá, CEP78060-900, Brazil

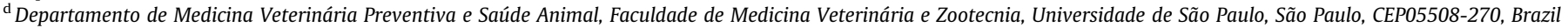 \\ e Laboratório de Virologia e Rickettsioses, Hospital Veterinário, Universidade Federal de Mato Grosso, Cuiabá, CEP78060-900, Brazil
}

\section{A R T I C L E I N F O}

\section{Article history:}

Received 2 February 2012

Accepted 22 February 2013

\section{Keywords:}

Equid

EIAV

Seroprevalence

Risk factor

Mato grosso state

Brazil

\begin{abstract}
A B S T R A C T
Serum samples collected from 547 equids in the Pantanal region of Brazil were evaluated for antibodies to Equine Infectious Anemia Virus (EIAV) by the agar gel immunodiffusion test. Risk factors associated with EIAV seropositivity were evaluated and spatial dependence investigated using a Spatial Lag Model. EIAV prevalence on farms in the Pantanal was $52.0 \%$ (13/25) with adjusted prevalence between equids of $31.5 \%$ (17.4-48.8\% 95\% CI). Intra-herd prevalence ranged from 5.0 to $77.0 \%$. Statistical analysis demonstrated that farms and animals in regularly flooded areas had respectively 60 and 146 fold higher chance to be sero-positive than farms and animals located in non-flooded areas. Spatial Lag Model results were generally consistent with this conclusion although there was a negative spatial correlation between farms located within in regularly inundated regions, suggesting that other factors, such as management practices, probably play a significant role in transmission of EIAV. Equids with clinical signs were 3.74fold more likely to be sero-positive than those without clinical signs. The results of this work reveal a high prevalence of EIAV in the Pantanal area of Brazil demonstrating that equids reared in this region are at great risk of infection.
\end{abstract}

(c) 2013 Elsevier Ltd. All rights reserved.

\section{Introduction}

Equine Infectious Anemia (EIA) is an important infection of horse breeding in Brazil. It is caused by Equine Infectious Anemia virus (EIAV), an enveloped RNA virus of the Lentivirus genus of the Retroviridae family (Gregg and Polejaeva, 2009) that affects all members of the family Equidae and is distributed worldwide (Issel and Coggins, 1979). EIA is sometimes referred to as 'swamp fever' because it is most prevalent in warm wet regions where insect vectors play significant role in the transmission of EIAV among horses (Stein et al., 1942). All large biting flies including Stomoxys calcitrans (stable fly) and Tabanus sp. (horse fly) are responsible for the transmission (Issel and Foil, 1984). Transmission is mechanical, the virus does not replicate in insects, and thus infection only occurs if the feeding of the insect is interrupted. Additionally, EIAV transmission may occur in utero although the incidence is generally low unless the pregnant mare experiences a clinical episode

\footnotetext{
* Corresponding author. Tel.: +55 65 36158662x211.

E-mail address: danmoura@ufmt.br (D.M. Aguiar).
}

with consequent high tissue-associated viral loads (Kemen and Coggins, 1972; McConnico et al., 2000). Other important transmission route is an iatrogenic form that happens in blood transfusions or by contaminated needles, surgical instruments and equine accessories (Mealey, 2007).

In Brazil, EIA was first diagnosed in 1968 by Dupont and since then it has been an obstacle in the Brazilian horse breeding (Almeida et al., 2006) mainly because prevalence rates indicate endemic infection in many areas of Brazil (Franco and Paes, 2011). According to the last EIA census in 1998 based on the results of official laboratory tests registered on the Brazilian Ministry of Agriculture, the EIA prevalence in Brazil is approximately 3\%, whereas it was about 24\% in south area of the Pantanal and Amazon regions (Silva et al., 1999a; Aguiar et al., 2008).

The Pantanal ecosystem is the largest tropical wetland area of the world. Situated among two Brazilian states (Mato Grosso and Mato Grosso do Sul) and in portions of Bolivia and Paraguay, the Pantanal comprises periodically inundated and non-inundated savannas (Cerrado biome) (Cunha and Junk, 2009). During rainy season, tabanids (Tabanus sp.) remain in high number in the 
flooded areas of Pantanal and present a great risk for EIAV transmission (Silva et al., 1999a). Horses and mules are economically important in the Pantanal because they are indispensable for livestock management and provide a practical means of transport in flooded areas (Cunha and Junk, 2009). However, this region experiences an annual rainy season (November to March), that promotes significant expansion in tabanid populations (Tabanus sp.) especially in flooded areas thereby increasing the risk for EIAV transmission (Silva et al., 1999a).

Clinical signs following exposure to EIAV can be highly variable ranging from a loss of life to the complete absence of disease. However, horses commonly experience an acute clinical episode, lasting one to three days in which the main disease signs are fever and thrombocytopenia. This is often followed by a chronic disease phase characterized by episodic bouts of fever, thrombocytopenia, depressed neurologic signs, anemia, edema and cachexia. After 12 to 24 months the frequency of disease episodes diminish and the horse will enter a prolonged phase, the inapparent carrier state where it is devoid of overt clinical signs (Vallee and Carre, 1904; Gregg and Polejaeva, 2009).

In response to the economic and animal welfare aspects of EIA the Brazilian government established a National Program of Equine Health to improve control of the disease. In this program infected equids are identified using the agar gel immunodiffusion test (AGID) (Coggins and Norcross, 1969). EIAV sero-positive equids are either humanely euthanized or placed in quarantine (Brasil, 2004).

Considering the importance of horse breeding as an essential segment of agribusiness in Brazil and at the Pantanal region, the present study aimed to determine the seroprevalence of EIAV infection in working equids from Poconé municipality, state of Mato Grosso, Brazil. Possible risk factors associated with viral infection and spatial analyses were also evaluated.

\section{Materials and methods}

\subsection{Study site}

The study was performed in the municipality of Pocone (16 ${ }^{\circ} 15^{\prime} 24^{\prime \prime}$ S, 56 $56^{\circ} 32^{\prime \prime}$ 'W), $100 \mathrm{~km}$ southwest of Cuiabá (State capital), Mato Grosso State. Poconé is considered to be one of the different subregions of Pantanal (Silva et al., 1999a) with a wide variety of habitats ( $80 \%$ of the relative area of Poconé is in the regularly flooded area) (Cunha and Junk, 2009). The Pantanal is an ecosystem characterized by an annual flooding cycle which intensely varies over the years. According to the Instituto de Defesa Agropecuária do Estado de Mato Grosso (INDEA), Poconé had an equidae population of 19,854 animals in 2009 census.

\subsection{Sampling procedures}

The number of equines to be sampled was determined by the Herdacc software version 3, and was stipulated in 20 animals, considering the maximum (100\%) of herd sensibility (HSe) and specificity (HSp) to classify a farm as positive. The number of farms (clusters) to be studied was carried out with the CSurvey software version 1.5 based in a cluster sampling (Bennet et al., 1991), using estimated prevalence of $18 \%$ (Silva et al., 1999b), 10\% error and $99 \%$ confidence interval. Considering that 20 working equines would be sampled per cluster (farm), 25 farms were determined. The farms to be visited were randomly selected from those registered in the INDEA and were located in both flooded and non-flooded areas of Poconé municipality. Blood was also collected from the mules if present on sampling premises.

\subsection{Samples and health questionnaire}

Access to farms was by state and federal highways (MT-060, MT-360, MT-451 and BR-070), and the geographic coordinates of each location were obtained by eTREX Vista HCx GPS (Garmin ${ }^{\circledR}$, Kansas, USA). Samples were collected from January to July 2010, aseptically by jugular venipuncture with $21 \mathrm{G}$ needles suitable for vacuum tubes. The whole blood remained at room temperature in tubes for approximately $12 \mathrm{~h}$ to clot retraction. The serum obtained from each animal was identified and stored into $1.5 \mathrm{ml}$ microtubes at $-20^{\circ} \mathrm{C}$ until the test.

In occasion of blood collection a health questionnaire was also applied in order to identify possible risk factors to EIAV infection. Variables related to the location of farms, measures adopted in the farms to prevent and control EIA, individual equids characteristics and sanitary data were approached.

\subsection{Laboratory analysis}

Serum samples were tested for antibodies against the p26 protein of EIAV by the agar gel immunodifusion (AGID) test (Coggins and Norcross, 1969) using a commercial kit currently approved by the Brazilian government according to the manufacturer's instructions (Bruch Laboratories, Brazil).

\subsection{Prevalence and statistical analysis}

Prevalence values were calculated separately for animals and farms (herds). As farms with different herd sizes were evaluated, the apparent animal prevalence estimate was adjusted based on herd size of each analyzed farm according to the Formulae (1). The calculation of apparent prevalence, standard error, 95\% confidence interval and design effect was performed by means of the Complex Sample Analyzes application of SPSS 16.0 for Windows. Intra-cluster correlation coefficient $(\rho)$ was determined by the Formulae (2) (Otte and Gumm, 1997), where $X_{n}$ is the average herd size. The true animal prevalence was calculated considering sensibility (0.98) and specificity (1.0) values of the AGID tests (Almeida et al., 2006). Predictive values of the diagnostic test for animal and herd prevalence were calculated according to Thrusfield (2005).

The association among positivity to EIAV antibodies and independent variables were analyzed considering adjusted values of herd size by Qui-Square $\left(\chi^{2}\right)$ or Fisher exact Tests, and $P \leqslant 0.05$ was considered significant. The statistical software SPSS version 16.0 for Windows was used for the analysis. Prevalence values for age groups were evaluated by Qui-square for trend and was performed by Epilnfo 3.5.2 for Windows.

The Spatial Lag Model (Spatial AutoRegressive - SAR) was performed according to Câmara et al. (2002), using the Formulae (3), where $Y$ is the dependent variable considered as the prevalence of positive animals per farm, $W$ is the spatial proximity matrix, $W Y$ expresses a spatially lagged dependent variable for $Y, X$ signifies the explanatory variables, $\varepsilon$ is a vector of error terms, $\rho$ is the spatial autoregressive coefficient and $\beta$ is regression coefficients of variables. The analyzed variables were: Animal Density (AD), Equids Function (EF), Isolated Positive Animal (IPA), Weaning Foals (WF), Distance between Herds (DH) and Location of Farms (LF). The initial model tested was represented by the Formulae (4). The value of $W$ was obtained considering all farms as neighbors since the border of each farm cannot be determined, and the weight of the neighborhood as the inverse of the distance between farms as their geographical coordinates. In order to obtain a summarized model considering only significant variables, each variable was tested together and separately.

The present study was approved by the Bioethical Committee in Animal Research of the Federal University of Mato Grosso. 


\section{Results}

Of the 25 farms employed in this study (Fig. 1), 11 (44.0\%) containing 234 of the equids sampled were located in non-flooded areas (farms \#1, \#2, \#6, \#8, \#9, \#12, \#13, \#17, \#22, \#23 and \#25) whereas 14 (56.0\%) with 313 sampled equids were located in regularly flooded areas (farms \#3, \#4, \#5, \#7, \#10, \#11, \#14, \#15, \#16, \#18, \#19, \#20, \#21 and \#24).

The total area of the farms ranged from 75 to 8498 hectares with an average of 4029 hectares. Equid populations on these farms ranged from 25 to 200 animals, with an average of 90 equids per farm. Animal density was calculated and ranged from 0.007 to 0.53 equids per hectare (average $\sim 0.085$ and median 0.028 ). On 20 farms equids were maintained solely for work whereas on the remaining 5 farms some equids were used for leisure, sportive practices (team penning) and agriculture exposition. Samples were collected from a total of 547 equids, comprising 500 horses (Equus caballus) and 47 mules (Equus caballus $\times$ Equus asinus). These animals ranged from 3 to 17 years with 77 (14.1\%) female and 470 male (85.9\%).
Table 1 shows the apparent and true prevalence values for herds and animals. Prevalence rates intra-herd ranged from $5.0 \%$ to $77.0 \%$ with an average prevalence value of $23.0 \%$. According to the age group, prevalence values were $20.2 \%$ (Odds Ratio 1.0) for equids aged 0 to 4 years, $21.4 \%$ (OR 1.07 ) for $4-8$ years, $39.2 \%$ (OR 2.55) for $8-12$ years and $40.0 \%$ (OR 2.63) for $>12$ years $(P<0.01)$.

Results of the association between positive farms and animals and the variables studied are shown in Tables 2 and 3. Analysis showed that farms located within regularly flooded areas were 60 times more likely to have an EIAV positive animal than farms in non-flooded areas. According to the adjusted $\chi^{2}$ tests, equids living in regularly flooded areas were 146.4 times more likely to be sero-positive to EIAV than equids living in non-flooded areas. Furthermore, equids with clinical signs (weight loss, pale mucous membranes, rough hair coat and edema) were 3.74 times more likely to possess antibodies to this virus than equids without clinical signs. Spatial Lag Model indicated that farms located in the regularly flooded areas were associated with presence of

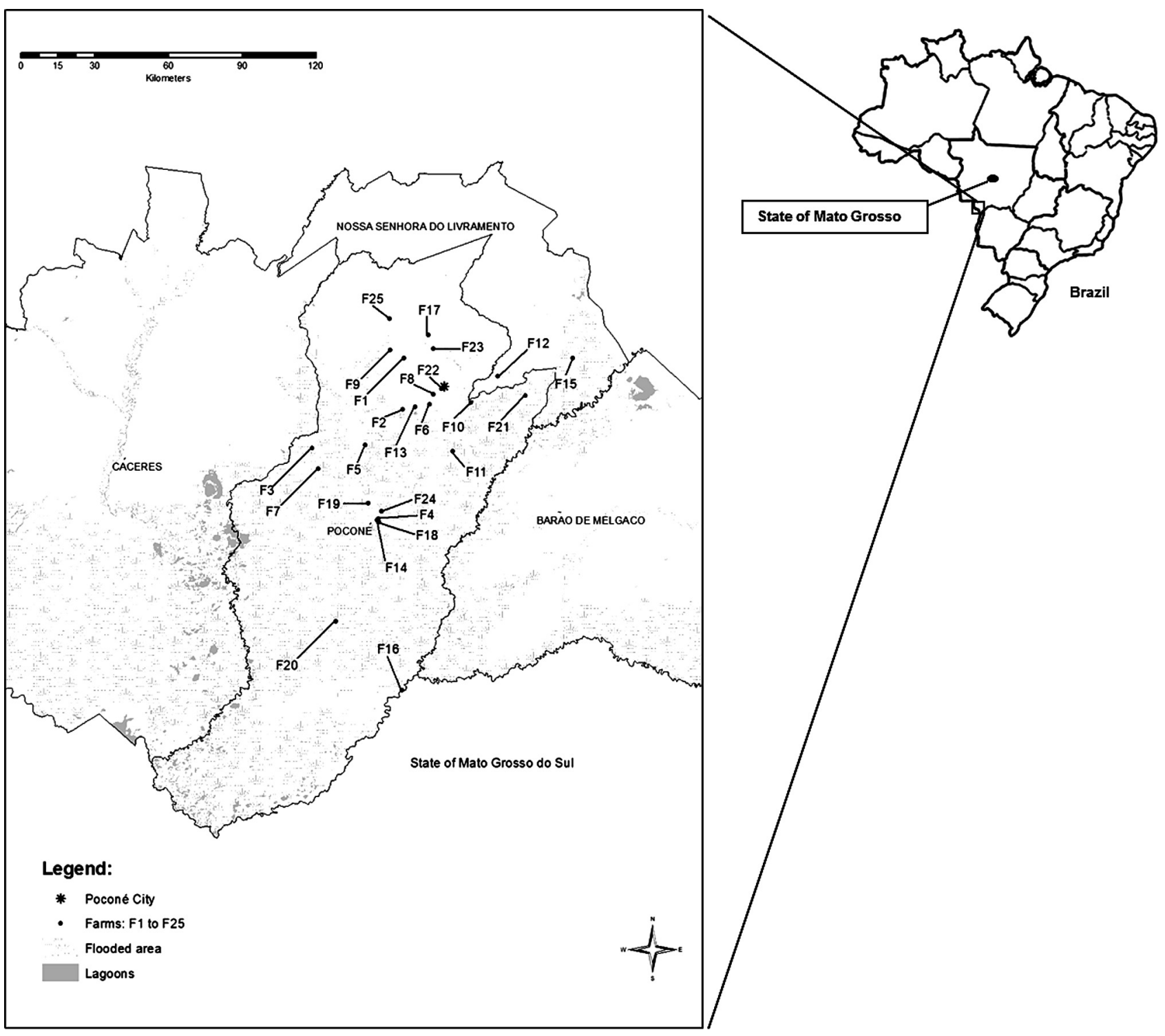

Fig. 1. The Poconé municipality and neighboring municipalities of Mato Grosso State, Brazil, indicating the urban area (Poconé city) and 25 farms where equids were sampled in the present study. 
Table 1

Crude and adjusted values of the prevalence of Equine Infectious Anemia Virus infection on farms and animals from Poconé municipality, Mato Grosso State, Brazil.

\begin{tabular}{|c|c|c|c|c|c|c|c|c|c|c|}
\hline Sample & $n$ & Pos & $\%$ & Prevalence $^{\mathrm{a}}(\%)$ & $95 \%$ IC & SE (\%) & $\mathrm{DE}$ & rho & PPV (\%) & NPV (\%) \\
\hline Herd & 25 & 13 & 52.0 & 52.0 & $38.1-65.8$ & 7.0 & & & 100 & 100 \\
\hline Animal & 547 & 134 & 24.5 & 31.5 & $17.4-48.8$ & 7.8 & 16.6 & 0.7 & & \\
\hline
\end{tabular}

$n=$ number tested.

Pos $=$ number of positives.

$\mathrm{SE}=$ standard error.

$\mathrm{DE}=$ design effect calculated in clusters samples.

rho $=$ intra-cluster correlation calculated according formulae (2).

PPV = positive predictive Value.

NPV = negative predictive Value.

a Calculated according to Formulae (1) and considering sensibility (0.98) and specificity (1.0) values.

Table 2

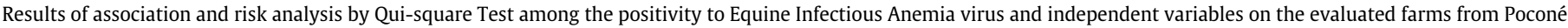
municipality, Brazilian Pantanal.

\begin{tabular}{|c|c|c|c|c|c|c|}
\hline \multirow[t]{2}{*}{ Variables } & \multicolumn{6}{|c|}{ Number of farms } \\
\hline & Sampled & Positive & $\%$ & OR & $95 \%$ IC & $P$ \\
\hline \multicolumn{7}{|c|}{$\begin{array}{l}\text { Control measures of EIAV } \\
\text { Isolation of seropositive }\end{array}$} \\
\hline Yes & 16 & 6 & 37.5 & & & \\
\hline No & 09 & 7 & 77.8 & 5.8 & $0.9-37.8$ & 0.09 \\
\hline \multicolumn{7}{|l|}{ Weaning foals } \\
\hline Until 5 months & 11 & 5 & 45.5 & & & \\
\hline Over 5 months & 14 & 8 & 57.1 & 1.6 & $0.3-7.8$ & 0.56 \\
\hline \multicolumn{7}{|c|}{ Distance between herds } \\
\hline Until 2 km & 5 & 2 & 40.0 & & & \\
\hline Over 2 km & 20 & 11 & 55.0 & 1.8 & $0.2-13.4$ & 0.64 \\
\hline \multicolumn{7}{|l|}{ Function of equids } \\
\hline Work and other ${ }^{\mathrm{b}}$ & 5 & 0 & 0 & & & \\
\hline Work & 20 & 13 & 65.5 & - & - & 0.00 \\
\hline \multicolumn{7}{|l|}{ Location of farms } \\
\hline Non-flooded & 11 & 1 & 9.1 & & & \\
\hline Flooded areas & 14 & 12 & 85.7 & 60.0 & $4.8-763.0$ & 0.00 \\
\hline \multicolumn{7}{|l|}{ Animal density } \\
\hline Until 0.028 equids & 11 & 6 & 54.5 & & & \\
\hline Over 0.028 equids & 14 & 7 & 50.0 & 0.83 & $0.1-4.0$ & 0.82 \\
\hline
\end{tabular}

${ }^{\mathrm{b}}$ Equids were also dedicated to leisure, sportive practices and agriculture exposition.

Table 3

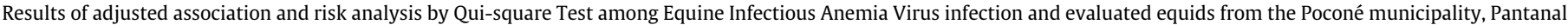
region of Brazil.

\begin{tabular}{|c|c|c|c|c|c|c|}
\hline \multirow[t]{2}{*}{ Variables } & \multicolumn{2}{|l|}{ Number (\%) } & \multicolumn{4}{|c|}{ Adjusted analysis $^{\mathrm{c}}$} \\
\hline & Sampled & Positive & $\%$ & OR & $95 \% \mathrm{CI}$ & $P$ \\
\hline \multicolumn{7}{|l|}{ Species } \\
\hline Mules & $47(8.6)$ & $13(27.7)$ & 26.1 & & & \\
\hline Equine & $500(91.4)$ & $121(24.2)$ & 31.5 & 1.30 & $0.47-3.53$ & 0.59 \\
\hline \multicolumn{7}{|l|}{$\operatorname{Sex}$} \\
\hline Female & $77(14.1)$ & $25(32.5)$ & 34.5 & & & \\
\hline Male & $470(85.9)$ & $109(23.2)$ & 30.2 & 0.82 & $0.20-3.24$ & 0.76 \\
\hline \multicolumn{7}{|l|}{ Saddle and tacks } \\
\hline Own & $73(13.3)$ & $0(0)$ & 0 & & & \\
\hline Shared & $474(86.7)$ & $134(28.3)$ & 35.6 & - & - & 0.26 \\
\hline \multicolumn{7}{|c|}{ Vaccine against other infections } \\
\hline No & $252(46.1)$ & $41(16.3)$ & 19.4 & & & \\
\hline Yes & $295(53.9)$ & $93(31.5)$ & 40.6 & 2.83 & $0.58-13.82$ & 0.18 \\
\hline \multicolumn{7}{|l|}{ Localization of farms } \\
\hline Non-flooded areas & $234(42.7)$ & $2(0.85)$ & 0.6 & & & \\
\hline Flooded areas & $313(57.3)$ & $132(42.1)$ & 48.4 & 146.4 & $15.9-1346.4$ & 0.00 \\
\hline \multicolumn{7}{|l|}{ Clinical signs } \\
\hline No & $517(94.5)$ & $119(23.0)$ & 29.0 & & & \\
\hline Yes & $30(5.5)$ & $15(50.0)$ & 60.5 & 3.74 & $1.06-13.15$ & 0.03 \\
\hline
\end{tabular}

c Adjusted values calculated according weight of each animal in the herd. 
sero-positive equids but a negative spatial correlation was found between farms in regard to EIA prevalence (Table 4 ).

\section{Discussion}

This study demonstrated widespread dissemination of EIAV in the Pantanal region of Brazil with $52.0 \%$ of the farms tested having at least one positive animal. The high $\rho$ value (0.7) suggests variance in infection rates within equid herds is similar to that between herds maintained at different farms (Otte and Gumm, 1997).

Overall prevalence of serum antibodies against EIAV in individual animals was $31.5 \%$ which is consistent with previous results reported by Silva et al. (1999b) who found detectable infection rates of $24.8 \%$ in the Southern Pantanal (Mato Grosso do Sul State). However the prevalence of EIAV is not uniform throughout the Pantanal $(P<0.05)$ as seropositive animals were detected in only one of eleven surveyed farms (9.1\%) located within non-flooded regions compared to 12 of 14 farms (85.7\%) that were situated in regularly flooded areas. Furthermore the prevalence of EIAV in dry area equid populations is dramatically lower $(0.85 \%)$ than that observed in equids from regularly inundated regions (42.1\%).

The conclusion that there is a correlation between the maintenance of equids in regularly flooded regions and EIAV sero-positivity is strongly supported by results of association tests and spatial risk analysis. Swamps or wetlands particularly when coupled with warm temperatures provide very favorable moist environments for the growth of hematophagous insect populations and so it is likely that insect vector burdens will be higher in these areas than in those that are not prone to regular flooding (Issel and Coggins, 1979; Gregg and Polejaeva, 2009). Furthermore, in the Pantanal, insect vectors have been shown to play a significant role in EIA transmission in wild equine populations (Silva et al., 1999a). According to Barros and Foil (2007), if the blood meal is interrupted the probability that a tabanid vector will return to the original host or transfer to a new equid is inversely correlated with the distance between animals.

The results of Spatial Lag Model showed a negative spatial correlation among farms, suggesting that other factors, such as management practices, probably play a significant role in transmission of EIAV within the Pantanal. In this region, equids used exclusively for livestock management frequently share tack raising the possibility of fomite transmission via for example bridles and bits (Mealey, 2007) although our results do not support such an association. Instead a higher prevalence of EIAV was observed in vaccinated animals rather than unvaccinated equids suggesting that iatrogenic transmission may occur. Vaccines against encephalomyelitis and rabies virus are frequently used in the region (data not shown). Although statistical significance was not confirmed from the number of animals sampled in this study, there appeared to be a higher prevalence $(p=0.09)$ of EIAV on farms that did not segregate infected and non-infected equids compared to those that maintained spatial separation between the two groups, highlighting the relevance of the management practices on the control of this virus. Moreover no positive animal were found on farms that breed equids for leisure or agriculture exposition. This

Table 4

Spatial Lag Model according to different covariates and spatial autoregressive coefficient of the 25 farms evaluated in the Poconé, municipality, Brazilian Pantanal.

\begin{tabular}{lcc}
\hline Spatial lag model & $Y=-0.2876 W Y+1.66+0.2772 L F$ \\
\cline { 2 - 3 } Covariate & Estimate & $P$ \\
\hline Intercept & 1.6609 & 0.0022 \\
Location of farms & 0.2772 & 0.0005 \\
$\rho$ & -0.2876 & 0.0020 \\
\hline
\end{tabular}

result probably reflects more rigorous testing and management protocols to comply with the fact the Brazilian government only permits equidae with negative AGID test results to be transported on public highways.

In this study EIAV sero-prevalence was not statistically different between the sexes, a result that differs from that reported by Silva et al. (1999b) where males presented greater risk of infection than females. When prevalence by age was compared, the highest levels of sero-positivity were in older animals ( $>8$ years) consistent with longer exposure to potential transmission factors (Silva et al., 1999b).

Sero-prevalence among horses and mules was similar $(P>0.05)$. Unfortunately, there is little available information at present concerning the responses of mules to natural infection and their epidemiological importance in the transmission of EIAV. Experimentally infected mules yielded similar clinicopathological signs and laboratory findings to those observed in horses and ponies (Spyrou et al., 2003).

Of the 547 animals surveyed in this study 517 (94.5\%) showed no overt signs of disease which is consistent with previous observations that most equids have attained inapparent carrier status prior to detection (Issel and Coggins, 1979). However, 30 (5.5\%) equids had some clinical signs (weight loss, pale mucous membranes, rough hair coat and edema) at the time samples were collected of which half possessed antibodies against EIAV. Unfortunately, it was not possible to re-test any of these animals with negative AGID test results to determine if any subsequently became sero-positive. Nonetheless, this important epidemiological data suggests that transmission is still actively occurring in the region.

In conclusion, results presented here demonstrate a high prevalence of EIAV in the Brazilian Pantanal where the environmental factors such as regular flooding and husbandry practices play significant roles in the transmission of this virus.

\section{Acknowledgments}

We especially thank the reviewers for their valuable suggestions, Andréia L.T. Melo for her technical support with maps, Risia L. Negreiros for her support with the farms registered in the INDEA, Juliane V.T. Aguiar for language support and J. Daniels for being attempt throughout the accomplishment of this work. This work was supported by Fundação de Amparo a Pesquisa do Estado de Mato Grosso (FAPEMAT 446226/2009; research grant to DMA and graduating scholarships to RW).

\section{Appendix Formulae. (1)}

$\begin{aligned} \text { Weight }= & \frac{\mathrm{n} \text {. of equids in farm }}{\mathrm{n} . \text { of sampled equids }} \\ & \times \frac{\mathrm{n} \text {. of equids at the municipality }}{\mathrm{n} \text {. of equids in all sampled farms }}\end{aligned}$

Appendix Formulae. (2)

$\rho=\frac{\text { Design effect }-1}{X_{n}-1}$

Appendix Formulae. (3)

$Y=\rho W Y+X \beta+\varepsilon$ 
Appendix Formulae. (4)

$Y=\rho W Y+\beta_{0}+\beta_{1} A D+\beta_{2} E F+\beta_{3} I P A+\beta_{4} W F+\beta_{5} D H+\beta_{6} L F$

\section{References}

Aguiar, D.M., Cavalcante, G.T., Lara, M.C.C.S.H., Villlobos, E.M.C., Cunha, S.E.M. Okuda, L.H., Stéfano, E., Nassar, A.F.C., Souza, G.O., Vasconcelos, A.S., Labruna, M.B., Camargo, L.M.A., Gennari, S.M., 2008. Prevalência de anticorpos contra agentes virais e bacterianos em equinos do município de Monte Negro Rondônia, Amazônia Ocidental Brasileira. São Paulo, Brasil. Brazilian Journal of Veterinary Research and Animal Science 45, 269-276.

Almeida, V.M.A., Gonçalves, V.S.P., Martins, M.F., Haddad, J.P.A., Dias, R.A., Leite, R.C., Reis, J.K.P., 2006. Anemia infecciosa equina: prevalência em equídeos de serviço em Minas Gerais. Arquivos Brasileiros de Medicina Veterinária e Zootecnia 58, $141-148$.

Barros, A.T.M., Foil, L.D., 2007. The influence of distance on movement of tabanids (Diptera: Tabanidae) between horses. Veterinary Parasitology 144, 380-384.

Bennet, S., Woods, T., Liyanage, W.M., Smith, D.L., 1991. A simplified general method for cluster - sample surveys of health in developing countries. World Health Statistics 44, 98-106.

Brasil, 2004. Normas para a prevenção em o controle da Anemia Infecciosa Equina AIE. Instrução Normativa 45 de 15 de junho de 2004. Ministério da Agricultura, Pecuária e Abastecimento do Brasil, Diário Oficial, Brasília, DF, Brasil.

Câmara, G., Carvalho, M.S., Cruz, O.G., Correa, V., 2002. Análise espacial de áreas. INPE, 2002, São José dos Campos. <http://www.dpi.inpe.br/gilberto/livro/ analise/cap5-areas.pdf> (Accessed 30 Jan 2010).

Coggins, L., Norcross, N.L., 1969. Immunodiffusion reaction in equine infectious anemia. Cornell Veterinarian 60, 330-335.

Cunha, C.N., Junk, W.J., 2009. A preliminary classification of habitats of the Pantanal of Mato Grosso and Mato Grosso do Sul, and its relation to national and international wetland classification systems. In: The Pantanal Ecology biodiversity and sustainable management of a large neotropical seasonal wetland. Pensoft Publishers, Moscow, FD, Russia, pp. 127-141.
Franco, M.M.J., Paes, A.C., 2011. Anemia infecciosa equina Revisão de Literatura. Veterinaria e Zootecnia 18, 197-207.

Gregg, K., Polejaeva, I., 2009. Risk of equine infectious anemia virus disease transmission through in vitro embryo production using somatic cell nuclear transfer. Theriogenology 72, 289-299.

Issel, C.J., Coggins, L., 1979. Equine infectious anemia: current knowledge. Journal of American Veterinary Medical Association 174, 727-733.

Issel, C.J., Foil, L.D., 1984. Studies on equine infectious anemia virus transmission by insects. Journal of American Veterinary Medical Association 184, 293-297.

Kemen, M.J., Coggins, L., 1972. Equine infectious anemia: transmission from infected mares to foals. Journal of American Veterinary Medical Association $161,496-499$.

McConnico, R.J., Issel, C.J., Cook, S.J., Cook, R.F., Floyd, C., Bison, H., 2000. Predictive methods to define infection with equine infectious anemia virus in foals out of reactor mares. Journal of Equine Veterinary Science 20, 387-392.

Mealey, R.H., 2007. Equine infection anemia. In: Sellon, D.C., Long, M. (Eds.), Equine Infectious Diseases. Saunders Elsevier, St. Louis, MO, USA, pp. 213-219.

Otte, M.J., Gumm, I.D., 1997. Intracluster correlation coefficient of 20 infections calculated from the results of cluster-sample surveys. Preventive Veterinary Medicine 31, 147-150.

Silva, R.A.M.S., Abreu, U.G.P., Davila, A.M.R., Ramirez, L., 1999a. Swamp fever in wild horses from the Pantanal, Brazil. Revue Elevge de Medicine Veterinaire des Pays Tropicaux 52, 99-101.

Silva, R.A.M.S., Davila, A.M.R., Iversson, L.B., Abreu, U.G.P., 1999b. Equine viral diseases in the Pantanal, Brazil. Studies carried out from 1990 to 1995 . Revue Elevge de Medicine Veterinaire des Pays Tropicaux 52, 9-12.

Spyrou, V., Papanastassopoulou, M., Psychas, V., Billinis, Ch., Koumbati, M., Vlemmas, J., Koptopoulos, G., 2003. Equine infectious anemia in mules: virus isolation and pathogenicity studies. Veterinary Microbiology 95, 49-59.

Stein, C.D., Lotze, J.C., Mott, L.O., 1942. Transmission of equine infectious anemia by the stablefly, Stomoxys calcitrans, the horse fly, Tabanus sulcifrons (Macquart), and by injection of minute amounts of virus. American Journal of Veterinary Research 3, 183-193.

Thrusfield, M., 2005. Diagnostic testing. In: Veterinary Epidemiology, third ed. Blackwell Science, Oxford, DQ, UK, pp. 305-330.

Vallee, H., Carre, H., 1904. Sur la natur infectieuse de l'anenie du cheval. Comptes Rendus de l'Académie des Sciences - Series III 139, 331-333. 